\title{
Evaluation of a new electronic spirometer: the Vitalograph "Escort" spirometer
}

\author{
N Wiltshire, A H Kendrick
}

\begin{abstract}
Background - The "Escort" spirometer is a lightweight, hand held spirometer employing a Fleisch pneumotachograph. Measurements of forced expiratory volume in one second $\left(F E V_{1}\right)$, forced vital capacity (FVC), and peak expiratory flow (PEF) are obtained from a single FVC manoeuvre. Results are displayed on a small liquid crystal display, but there is no graphical display. The performance of the Escort spirometer has been compared with that of a wedge bellows spirometer (Vitalograph $S$ model) and a Wright PEF meter.
\end{abstract}

Methods - One hundred and thirteen subjects performed three FVC manoeuvres on the wedge bellows and Escort spirometers and three PEF manoeuvres on the Wright meter. The best reading for each index was recorded. In 21 of the subjects comparison of a Wright manoeuvre with an FVC manoeuvre on the Escort spirometer was performed, whilst in three subjects the effect of repeated blows was studied.

Results - The FEV ranged from 0.5 to $5 \cdot 4$ litres, FVC from 1.05 to 6.2 litres, and PEF from 100 to $7251 / \mathrm{min}$. The mean (SD) difference for the $F E V_{1}$ was -0.05 $(0 \cdot 15)(95 \%$ confidence interval $(95 \% \mathrm{CI})$ -0.07 to -0.02$)$ litres, for FVC $0.03(0.28)$ $(95 \% \mathrm{CI}-0.02$ to +0.08$)$ litres, and for PEF 1.68 (50.6) (95\% CI -7.7 to $+11 \cdot 1)$ $1 / \mathrm{min}$. The differences were positively correlated with the mean reading for PEF and FVC but not for $F E V_{1}$. The Wright PEF manoeuvre performed on the Escort produced significantly higher PEF readings (mean difference -22.9 litres). There was no significant effect of repeated FVC manoeuvres on any of the indices.

Conclusions - The Escort spirometer compares extremely well with a wedge bellows spirometer for measurement of FEV 1 and FVC, whilst yielding results of PEF from an FVC manoeuvre which are comparable to those obtained from a Wright meter. It can be recommended for use as a portable hand held spirometer.

(Thorax 1994;49:175-178)
Simple measurements of lung function such as the forced expiratory volume in one second $\left(\mathrm{FEV}_{1}\right)$, forced vital capacity (FVC), and peak expiratory flow (PEF) are widely used in the assessment of airway function to measure the effects of drugs, in epidemiological research, and in clinical trials.

There are presently several relatively inexpensive, portable devices for measuring PEF, $\mathrm{FEV}_{1}$, and FVC which have been shown to produce results that are comparable with less portable devices. ${ }^{12}$ The purpose of this study was to compare the characteristics and performance of a new spirometer (Escort; Vitalograph Ltd) with that of a Vitalograph wedge bellows spirometer and the Wright peak flow meter, and to compare its performance with the European ${ }^{3}$ and American ${ }^{4}$ (ATS) recommended standards.

\section{Methods}

EQUIPMENT

The Escort spirometer was loaned by the manufacturers and compared with a model $S$ wedge bellows spirometer and a standard Wright peak flow meter. The wedge bellows and the Wright meter were specifically calibrated for the study.

The Escort is a light weight ( $450 \mathrm{~g}$ ), hand held device powered by an integral, rechargeable Nicad battery with an operating time of 90 minutes. Measurements of PEF, $\mathrm{FEV}_{1}$, and FVC are obtained with an unheated Fleisch pneumotachograph which can be readily dismantled for autoclaving. The performance procedure and the results are displayed on a small liquid crystal display. There is no hard copy printout of either the trace or of the indices measured. Repeated measures update the values according to the ATS criteria. ${ }^{4}$

Volume calibration and linearity were assessed over the range 0-7 litres ATPS at $21^{\circ} \mathrm{C}$. Air was introduced in $500 \mathrm{ml}$ increments using a seven litre calibration syringe (Hans Rudolf, Model 4900). Flow calibration and linearity were assessed over the range $0-470$ $1 /$ min using rotameters (Fisher Controls Ltd). The resistance of the flow head was assessed by measuring the back pressure generated over the range of flow rates. 
SUBJECTS

One hundred and thirteen subjects were recruited from hospital staff and patients with various disorders. All measurements were made in the seated position and without nose clips.

\section{COMPARISON OF INSTRUMENTS}

Each subject performed three technically acceptable FVC manoeuvres on the wedge bellows and Escort spirometers and three PEF manoeuvres on the Wright meter. The order of the measurements was randomised, and all measurements were made at a single session. The measurements from the wedge bellows spirometer were accepted on the basis of visual inspection of the traces. The measurements from the Wright meter and from the Escort were accepted by observation of the subject during the performance of each manoeuvre. In all subjects the highest value was recorded. In 41 of the subjects all values were recorded to allow assessment for repeatability of the measurements.

Twenty one subjects performed three Wright manoeuvres (short blow) and three FVC manoeuvres (long blow) on both the Wright and Escort spirometers in a random order.

The effect of repeated FVC manoeuvres on the unheated pneumotachograph of the Escort was studied in three normal subjects who performed 30 FVC manoeuvres at one minute intervals. The Escort was calibrated before each series. Each index was recorded after each FVC manoeuvre.

\section{DATA ANALYSIS}

The data were analysed with the Minitab stat-

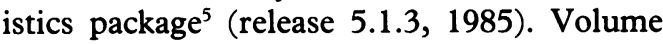
and flow linearity were assessed by linear regression analysis and analysis of variance as applied to regression.

Physiological performance was analysed by comparing the highest recorded values of $\mathrm{FEV}_{1}, \mathrm{FVC}$, and PEF of each subject obtained from each device. The data were analysed by method comparison analysis. ${ }^{6}$ This compares the difference between the measures from each device with the mean of those measures. The mean difference indicates the bias and the standard deviation of the differences indicates the error between the two techniques. The $95 \%$ confidence limits for the estimates of the mean difference and the limits of agreement (difference $\pm 2 S D$ ) were obtained for each index. The same analysis was applied to compare short blows with long blows. Differences were calculated as (Escort-wedge bellows/ Wright).

The repeatability of each of the measurements was assessed by calculating the standard deviation of the difference between the two closest values. The defined repeatability coefficient is twice the standard deviation ${ }^{6}$ which indicates the $95 \%$ probability limit within which the best two out of three readings would lie.
The effect of repeated efforts was assessed by using normal probability plots which relate the expected normal score for each data point to the actual value of the data point. If the plot produced a linear relation with a correlation coefficient of greater than $0.964 \quad(n=30$, $p=0.05)$ then the hypothesis of normality was accepted. ${ }^{7-9}$ The symmetry and height of the frequency distributions were assessed from the coefficients of skewness and kurtosis for each subject respectively. ${ }^{10}$ For a normal distribution the coefficient of skewness should be in the range \pm 0.51 , and the coefficient of kurtosis should have a value of about three. Fatigue effects were assessed by the coefficient of variation and analysis of variance. The $5 \%$ level of probability was taken as the level of significance.

\section{Results}

INSTRUMENT PERFORMANCE

The Escort was linear over the volume range of 0-7 litres $(\mathrm{n}=15, r=0.99, \mathrm{p}<0.001)$ and the flow range of $0-470 \mathrm{l} / \mathrm{min}(\mathrm{n}=6, r=0.99$, $\mathrm{p}<0.001)$. The mean (SD) resistance of the flow head over this flow range was 0.025 $(0.001) \mathrm{kPa} .1 / \mathrm{s}$.

\section{COMPARISON OF INSTRUMENTS}

From the 113 subjects tested, the $\mathrm{FEV}_{1}$ ranged from 0.50 to 5.4 litres, FVC from 1.05 to 6.20 litres, and PEF from 100 to $725 \mathrm{l} / \mathrm{min}$. Figure 1 shows the difference between measurements plotted against the mean of the two readings; table 1 gives the mean, SD, limits of agreement, ${ }^{6}$ and the $95 \%$ confidence limits of the differences.

The differences were significantly correlated with mean PEF $(r=0.33, \mathrm{~F}=15.5, \mathrm{df}=111$; $\mathrm{p}<0.001)$ and weakly correlated with the mean FVC $(r=0 \cdot 19, \mathrm{~F}=5 \cdot 18, \mathrm{df}=111, \mathrm{p}<0.05)$. There was no correlation in the case of FEV The relation for $\mathrm{PEF}$ was $\mathrm{PEF}_{\text {diff }}=0.117 \mathrm{PEF}_{\text {mean }}$ -46.3 , and for FVC was $\mathrm{FVC}_{\text {diff }}=$ $0 \cdot 05 \mathrm{FVC}_{\text {mean }}-0 \cdot 15$. There was therefore a significant proportional bias for PEF and FVC with the Escort giving higher readings at higher values for both PEF and FVC. Logarithmic transformation of the data did not remove this proportional bias.

The repeatability of each measurement was assessed in 41 subjects. For the wedge bellows the repeatability coefficient for $\mathrm{FEV}_{1}$ was 0.09 litres, for FVC 0.16 litres, and for the Wright meter PEF $11.71 / \mathrm{min}$. For the Escort FEV was 0.07 litres, FVC 0.17 litres, and PEF $19.41 / \mathrm{min}$, showing that the repeatability of the readings for the Escort was as good as those from the wedge bellows but not as good as those from the Wright meter.

The results of the comparison of short (Wright manoeuvre) $v$ long (FVC manoeuvre) are shown in fig 2 . On the Wright meter the short blow produced readings which were on average $12 \cdot 1 \mathrm{l} / \mathrm{min}$ greater than the long blow, the differences being significant (paired $\mathrm{t}=3.09, \mathrm{df}=20, \mathrm{p}<0.01$; limits of agreement -23.8 to $48 \cdot 1 \mathrm{l} / \mathrm{min})$. A greater average 

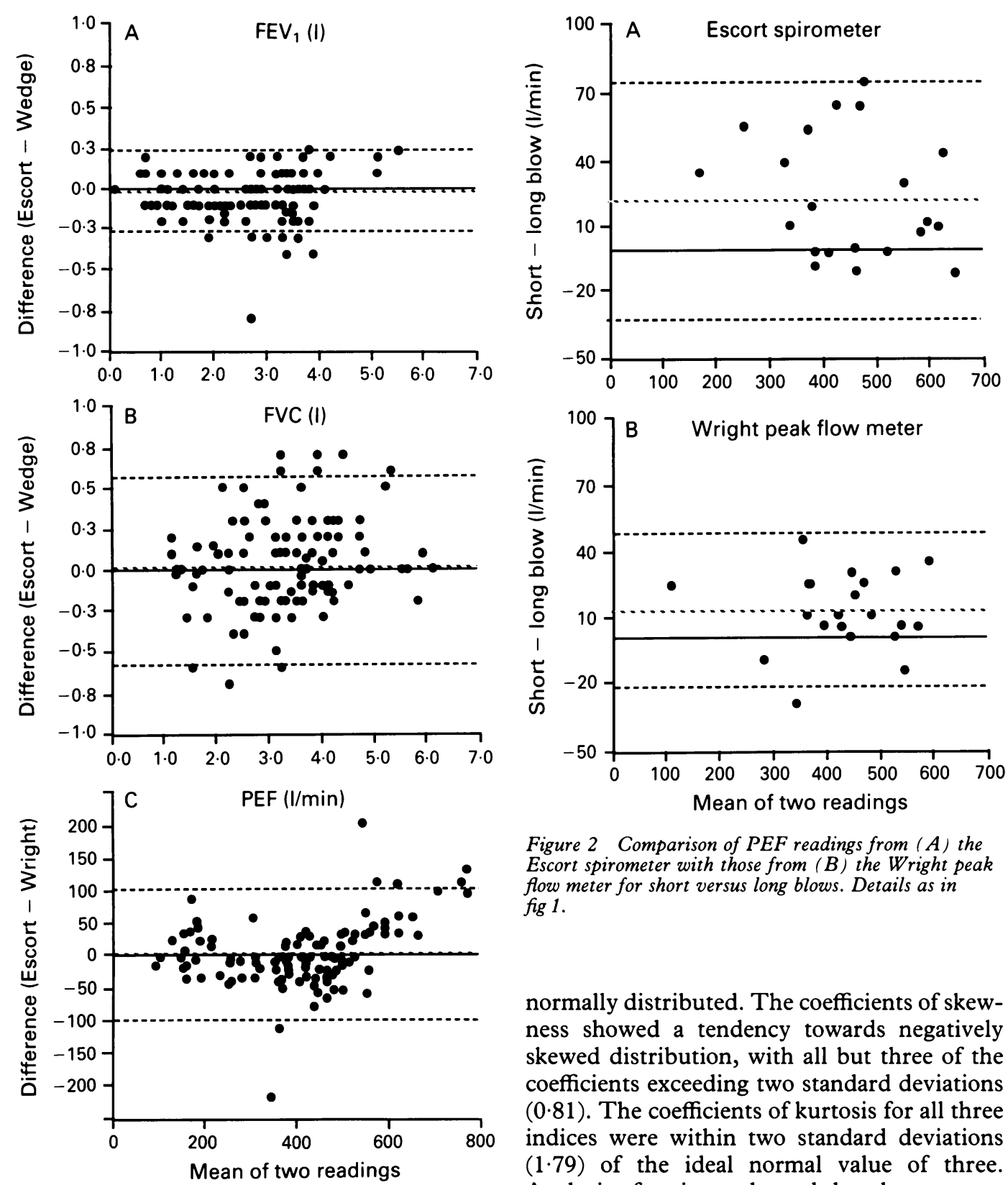

Figure 1 Comparison of ( $A$ ) FEV, (B) FVC, and (C) $P E F$ readings of the Escort spirometer with those of the Vitalograph wedge bellows spirometer and the Wright peak flow meter. The difference is plotted against the mean of the two readings. Solid line $=z e r o$ line, dotted line $=$ mean difference, and dashed line $= \pm 2 S D$.

difference $(22.91 / \mathrm{min})$ was obtained on the Escort (paired $\mathrm{t}=3.83, \mathrm{df}=20, \mathrm{p}<0.001$; limits of agreement -23.8 to $48 \cdot 11 / \mathrm{min}$ ).

For each index the correlation coefficients from the normal probability plots, the coefficients of variation, skewness, and kurtosis for each subject and each index are given in table 2. The correlation coefficients for normal distribution showed that, with the exception of PEF and FVC in subject 3, the indices were

Table 1 Mean, standard deviation, limits of agreement, and $95 \%$ confidence limits for the difference between the devices (Escort-Vitalograph/Wright meter)

\begin{tabular}{lrlll}
\hline & Mean & $S D$ & Limits of agreement & $95 \%$ confidence limits \\
\hline FEV (litres) & -0.05 & 0.15 & -0.35 to 0.26 & -0.07 to -0.02 \\
FVC (litres) & 0.03 & 0.28 & -0.53 to 0.59 & -0.02 to +0.08 \\
PEF (1/min) & 1.68 & 50.6 & -101.2 to 102.9 & -7.70 to +11.1
\end{tabular}

$\mathrm{FEV}_{1}=$ forced expiratory flow in one second; $\mathrm{FVC}=$ forced vital capacity; $\mathrm{PEF}=$ peak expiratory flow.

Figure 2 Comparison of $P E F$ readings from $(A)$ the Escort spirometer with those from $(B)$ the Wright peak flow meter for short versus long blows. Details as in fig 1 .

normally distributed. The coefficients of skewness showed a tendency towards negatively skewed distribution, with all but three of the coefficients exceeding two standard deviations $(0 \cdot 81)$. The coefficients of kurtosis for all three indices were within two standard deviations (1.79) of the ideal normal value of three. Analysis of variance showed that there was no significant downward trend over the 30 FVC manoeuvres. The occurrence of the lowest and highest test result for each index for each subject is also given in table 2 and shows that the lowest values do not occur at the end of the 30 FVC manoeuvres.

\section{Discussion}

Electronic hand held spirometers have several potential advantages over either water filled or bellows type spirometers, notably portability and ease of operation. The direct digital readout offered by these instruments is regarded as a major time saving advantage. However, although some of these spirometers are quite accurate, ${ }^{12}$ some electronic spirometers are inaccurate when compared with standard volume displacement spirometers. ${ }^{11-14}$

We have assessed the performance of the Escort spirometer and compared its performance with that of the Vitalograph wedge bellows spirometer and the Wright peak flow meter, both of which are widely used with well established limits for reliability and accuracy. ${ }^{115-17}$ 
Table 2 Correlation coefficients ( $\mathrm{r}$ ) for the normal probability plots, mean and standard deviation (SD), coefficients of variation $(C V \%)$, skewness $\left(g_{1}\right)$ and kurtosis $\left(g_{2}\right)$, and the occurrence of the lowest and highest values for the PEF, FEV, and FVC for the $30 \mathrm{FVC}$ manoeuvres in each subject from the Escort spirometer

\begin{tabular}{|c|c|c|c|c|c|c|c|c|c|}
\hline Index & Subject & $r$ & Mean & $S D$ & $C V^{\%} \%$ & $g$, & $g_{2}$ & Lowest & Highest \\
\hline PEF (litres) & $\begin{array}{l}1 \\
2 \\
3\end{array}$ & $\begin{array}{l}0.997 \\
0.964 \\
0.958\end{array}$ & $\begin{array}{l}586 \cdot 4 \\
445 \cdot 0 \\
581 \cdot 2\end{array}$ & $\begin{array}{l}10 \cdot 4 \\
35 \cdot 6 \\
18.5\end{array}$ & $\begin{array}{l}1 \cdot 8 \\
8 \cdot 0 \\
3 \cdot 2\end{array}$ & $\begin{array}{r}0.09 \\
0.87 \\
-0.77\end{array}$ & $\begin{array}{l}2 \cdot 54 \\
3 \cdot 67 \\
2 \cdot 84\end{array}$ & $\begin{array}{r}2 \\
17 \\
19\end{array}$ & $\begin{array}{l}21 \\
30 \\
25\end{array}$ \\
\hline $\mathrm{FEV}_{1}$ (litres) & $\begin{array}{l}1 \\
2 \\
3\end{array}$ & $\begin{array}{l}0.982 \\
0.970 \\
0.952\end{array}$ & $\begin{array}{l}4 \cdot 10 \\
3 \cdot 10 \\
3 \cdot 70\end{array}$ & $\begin{array}{l}0.07 \\
0.25 \\
0.06\end{array}$ & $\begin{array}{l}1.7 \\
8.1 \\
1.6\end{array}$ & $\begin{array}{l}-0.52 \\
-0.49 \\
-0.93\end{array}$ & $\begin{array}{l}3.27 \\
3.98 \\
3.45\end{array}$ & $\begin{array}{r}1 \\
23 \\
3\end{array}$ & $\begin{array}{l}29 \\
30 \\
13\end{array}$ \\
\hline FVC $(1 / \mathrm{min})$ & $\begin{array}{l}1 \\
2 \\
3\end{array}$ & $\begin{array}{l}0.994 \\
0.985 \\
0.970\end{array}$ & $\begin{array}{l}5 \cdot 80 \\
3 \cdot 50 \\
4 \cdot 10\end{array}$ & $\begin{array}{l}0.21 \\
0.40 \\
0.07\end{array}$ & $\begin{array}{l}3.6 \\
8.8 \\
1.7\end{array}$ & $\begin{array}{l}-0.08 \\
-0.57 \\
-0.84\end{array}$ & $\begin{array}{l}2 \cdot 19 \\
3 \cdot 05 \\
4 \cdot 66\end{array}$ & $\begin{array}{r}5 \\
17 \\
15\end{array}$ & $\begin{array}{l}6 \\
2 \\
5\end{array}$ \\
\hline
\end{tabular}

$\mathrm{PEF}=$ peak expiratory flow $\mathrm{FEV}_{1}=$ forced expiratory volume in one second; $\mathrm{FVC}=$ forced vital capacity.

Assessment of performance showed that, over the volume and flow ranges tested, the device was linear. The resistance produced over increasing flow rates was within both the ATS and European standards. We were unable to test the resistance of the device above $470 \mathrm{l} / \mathrm{min}$ because of equipment limitations. Maximum volume and test duration both exceeded the recommended standards.

The Escort produced values of $\mathrm{FEV}_{1}, \mathrm{FVC}$, and PEF that agreed closely with those obtained from the wedge bellows spirometer and the Wright meter. The mean differences were small although the limits of agreement were wide. This was particularly so for PEF, which is more dependent on the force of the initial portion of the FVC manoeuvre. The Escort tended to underestimate the $\mathrm{FEV}_{1}$ and to overestimate the PEF and FVC. The magnitude of the differences increased for PEF and FVC at higher readings indicating a tendency to over-read at these levels compared with standard equipment. It is known that the response of a Wright meter is curvilinear compared with an optimised Fleisch pneumotachograph over the flow range of $68-730$ $1 /$ min. ${ }^{18}$ Pneumotachographs are linear over their working range and so PEF measurements on the Escort should be reliable within this range. It is recognised that, at the extremes of this range, FVC is likely to be unreliable because the integration of flow to give volume is inaccurate at these extremes.

It is known that the $\mathrm{FEV}_{1}$ can be up to $8 \%$ greater on the wedge bellows spirometer when measured on the Ohio rolling seal or Stead Wells spirometer. ${ }^{151619}$ Similarly we found a lower FEV, on the Escort. On the Escort, the PEF is printed out as part of an FVC manoeuvre, while on the Wright meter a short sharp blow is required. A long blow tends to underestimate PEF to a variable extent on both instruments, a similar finding to that of Gunawardena et al. ${ }^{12}$ The mean difference is, however, small and unlikely to alter management.

We have also addressed the question whether repeated FVC manoeuvres with the unheated pneumotachograph will influence the readings, a problem recently discussed in the European standardisation document. ${ }^{3}$ Overall, all indices showed normal distributions, which indicates that 30 repeated FVC manoeuvres at one minute intervals do not significantly affect the pneumotachograph.

The major disadvantage of the Escort is the lack of a graphical display or the capability of printing the FVC curve. This is contrary to the recommendations ${ }^{34}$ of both the American and European societies for measurements performed in respiratory function laboratories. Apart from this, the overall performance of the Escort spirometer is very good. It is easy to use and will give accurate and reliable results if the tests are performed with care. The tests can be performed rapidly and a good estimate of PEF is obtained without the need for separate expiratory manoeuvres. The Escort can be recommended for use as a portable hand held spirometer.

We wish to thank all the subjects who cooperated in this study and Dr G Laszlo for help in the preparation of the manuscript.

1 Gunawardena KA, Houston K, Smith AP. Evaluation of the turbine pocket spirometer. Thorax 1987;42:689-93.

2 Jenkins SC, Barnes NC, Moxham J. Evaluation of a handheld spirometer, the Respiradyne, for the measurement of forced expiratory volume in the first second $\left(\mathrm{FEV}_{1}\right)$, forced expiratory volume in the first second $\left(\mathrm{FEV}_{1}\right)$,
forced vital capacity (FVC) and expiratory flow rate forced vital capacity (FVC) and expira
(PEFR). Br f Dis Chest 1988;82:70-5.

3 Quanjer PhH (ed). Standardized lung function testing, 1993 update. Eur Respir F 1993;6(Suppl 16).

4 American Thoracic Society Statement: Snowbird Workshop on Standardization of Spirometry. Am Rev Respir Dis 1979;119:831-8.

5 Ryan BF, Joiner BL, Ryan TA. Minitab. 2nd edn. Boston: Duxbury Press, 1985.

6 Bland JM, Altman DG. Statistical methods for assessing agreement between two methods of clinical measurement. agreement between two
Lancet 1986;i:307-10.

7 Joiner BL, Rosenblatt JR. Some properties of the range in samples from Tukey's symmetrical lambda distributions. f Am Stat Assoc 1971;66:394-8.

8 Filliben JJ. The probability plot correlation coefficient test for normality. Technometrics 1975;17:111-7.

9 Ryan TA, Joiner BL. Normal probability plots and tests for normality. Technical Report, Statistics Department, Pennsylvania State University, USA, 1986.

10 Snedecor GW, Cochran WG. Statistical methods. 7th edn. Iowa: Iowa State University Press.

11 Wever AMJ, Britton MG, Hughes DTD, Van der Plas KH, Wever-Hess J. Clinical evaluation of five spirometers: Monaghan M403, Pneumoscreen, Spirotron, Vicatest and Vitalograph. Eur $\mathcal{F}$ Respir Dis 1981;62:127-37.

12 Gunawardena KA, Smith AP. An evaluation of the LA3 Mk2 lung function analyser. Breath 1984;21:7-9.

13 Rode A, Shepard RJ. Accuracy of an electronic spirometera field trial. Respiration 1986;50:66-9.

14 Fitzgerald MX, Smith AA, Gaensler EA. Evaluation of 'electronic' spirometers. $N$ Engl $₹$ Med 1973;289:1283-8.

15 Wever AMJ, Britton MG, Hughes DTD. Evaluation of two spirometers. A comparative study of the Stead-Wells and the Vitalograph spirometers. Chest 1976;62:244-50.

16 Kendrick AH, Laszlo G. Performance of Vitalograph wedge-bellows spirometer - comparison with a rolling seal spirometer. Clin Phys Physiol Meas 1991;12:65-73.

17 Shepard RJ. Some observations on peak expiratory flow. Thorax 1962;17:39-48.

18 Miller MR, Dickinson SA, Hitchings DJ. The accuracy of Miller MR, Dickinson SA, Hitchings DJ. The accu
portable peak flow meters. Thorax 1992;47:904-9.

19 Gardner RM, Hankinson JL, West BJ. Evaluating commercially available spirometers. Am Rev Respir Dis 1980;121:73-82. 